\title{
Rancangan Catu Daya Cadangan SRAM Pada Z80 Trainer
}

\author{
Hidayat Tahir \\ Prodi Teknik Elektro \\ Universitas Negeri Gorontalo \\ Gorontalo, Indonesia \\ hidayat_s1elektro2013@mahasiswa.un \\ g.ac.id
}

\author{
Syahrir Abdussamad \\ Prodi Teknik Elektro \\ Universitas Negeri Gorontalo \\ Gorontalo, Indonesia \\ syahrirabdussamad@ung.ac.id
}

\author{
Iskandar Zulkarnain Nasibu \\ Prodi Teknik Elektro \\ Universitas Negeri Gorontalo \\ Gorontalo, Indonesia \\ zul.nasibu@ung.ac.id
}

\author{
Diterima : Desember 2020 \\ Disetujui : Desember 2020 \\ Dipublikasi : Januari 2021
}

\begin{abstract}
Abstrak-Z80 Trainer banyak digunakan dalam praktikum maupun alat bantu peraga terkait pembelajaran mikroprosesor. Dalam penggunaannya, Z80 Trainer menggunakan keypad untuk menulis kode sumber secara manual dan selanjutnya disimpan dalam memori secara volatile. Masalah yang sering terjadi adalah putusnya pasokan daya ke Z80 Trainer sehingga program yang telah ditulis tidak tersimpan dan harus ditulis kembali. Penelitian ini ditujukan untuk merancang dan mengontrol catu daya cadangan untuk SRAM di Z80 Trainer menggunakan baterai, yang mampu mendeteksi terputusnya suplai daya dari tegangan listrik PLN untuk memastikan bahwa data dan program yang telah ditulis dan tersimpan di memori tidak terhapus. Metode yang digunakan dalam penelitian ini adalah metode eksperimen dan perancangan alat yang dilaksanakan dilaboratorium. Penelitian ini telah menghasilkan alat yang dapat mengontrol catu daya cadangan berasal dari baterai melalui rangkaian switching control unit untuk SRAM di Z80 Trainer. Hasil pengujian unjuk kerja mendapati bahwa alat yang telah dibuat dapat mengontrol atau mengatur catu daya di SRAM disaat catu daya utama PLN terputus selama kurang lebih 26 hari dengan memakai baterai $L i$-Ion tipe 18650 berkapasitas $3000 m A h$. Pengujian lama waktu penggunaan alat $\mathrm{d}$ kondisi normal menggunakan catu daya cadangan mendapatkan hasil sekitar \pm 20 jam.
\end{abstract}

Kata Kunci-Z80 Trainer, SRAM, Catu Daya Cadangan.

Abstract- Z80 Trainer is widely used in practicum and teaching aids related to microprocessor learning. In use, the Z80 Trainer uses a keypad to write source code manually and then stored in volatile memory. The problem that often occurs is that the power supply to the $\mathbf{Z 8 0}$ Trainer is cut off so that the written program is not saved and has to be rewritten. This research is designed to build and control a backup power supply for SRAM on the Z80 Trainer using a battery, which can meet the power supply cut off from the PLN mains voltage to ensure that data and programs that have been written and stored in memory are not deleted. The method used in this research is the experimental method and the design of the tools carried out in the laboratory. This research has produced a tool that can control the backup power supply coming from the battery via a circuit of the switching control unit for the SRAM on the $\mathbf{Z 8 0}$ Trainer. The test results prove that the tool that has been made can control or build power in SRAM when the main power supply is cut off for less than 26 days using a $\mathrm{Li}$ Ion battery type 18650 with a capacity of $3000 \mathrm{mAh}$. Testing the length of time to use the tool under normal conditions using a backup power supply to get the result of about \pm 20 hours. Keywords-Z80 Trainer, SRAM, Backup Power Supply.

\section{Pendahuluan}

Dalam sistem mikroprosesor perangkat lunak dan perangkat keras keduanya sangat penting, yang satu tidak akan bekerja tanpa ada yang lainnya. Mikroprosesor merupakan sebuah chip yang digunakan sebagai otak atau pengolah utama dalam sistem komputer.

Salah satu mikroprosesor yang terkenal adalah $Z 80$ atau Microprocessor Evaluator Z-80 Trainer sering disebut juga Z80 Trainer, dan selanjutnya akan ditulis sebagai Z80 Trainer. Mikroprosesor ini diproduksi dan dipasarkan oleh Zilog mulai Juli 1976, dan digunakan secara luas pada komputer desktop maupun komputer embedded.

Z80 Trainer merupakan salah satu alat bantu yang mendasar dalam mempelajari suatu sistem mikroprosesor, digunakan sebagai modul sekaligus media pembelajaran mikrokomputer khususnya 8-bit, yang menggunakan central prosessing unit $(C P U)$ Z80 sebagai pemroses utamanya, dilengkapi dengan memori SRAM (Static Random Access Memory) dan read only memory (ROM), modul I/O (Input/Output), serta beberapa unit penyusun komputer lainnya.

Z80 Trainer lebih banyak digunakan dalam instansi pendidikan khususnya terkait dengan praktikum maupun sebagai alat bantu peraga dalam proses belajar mengajar terkait mikroprosesor. Z80 Trainer memiliki sekumpulan fungsi atau modul yang dapat digunakan atau diprogram dengan cara menekan tombol keypad yang mewakili fungsi/modul dimaksud, dan menggunakan media penyimpanan data/program pada $S R A M$.

Dalam penggunaan Z80 Trainer untuk pengisian data maupun penulisan program semuanya dilakukan secara 
manual melalui 36 tombol keypad yang tersedia, sehingga proses penulisan program dalam jumlah banyak atau panjang akan sangat melelahkan dan memakan waktu yang cukup lama. Program yang telah ditulis selanjutnya akan disimpan pada memori SRAM secara volatile, yang artinya selama memori dimaksud mendapatkan pasokan daya maka program yang tersimpan akan tetap ada, sebaliknya jika pasokan daya terputus maka semua program yang tersimpan akan terhapus.

Masalah yang sering terjadi selama ini adalah ketika pada saat penulisan program yang panjang dan membutuhkan waktu yang lama, tiba-tiba pasokan daya terputus. Akibatnya program akan terhapus, sehingga harus ditulis ulang dari awal. Hal ini selain menyebabkan waktu dan tenaga terbuang percuma, juga seringkali menimbulkan keengganan bagi yang ingin mempelajari mikroprosesor.

Tujuan dari penelitian ini yaitu merancang dan mengontrol catu daya cadangan untuk SRAM di Z80 Trainer menggunakan baterai, yang mampu mendeteksi terputusnya suplai daya dari tegangan listrik PLN untuk memastikan bahwa data dan program yang telah ditulis dan tersimpan di memori tidak terhapus.

Penelitian tentang Z80 Trainer ini sebelumnya sudah ada, akan tetapi hanya memfokuskan penyusunan modul praktikum sistem mikroprosesor Z80 menggunakan alat bantu program aplikasi Z80 simulator dengan tujuan penelitiannya adalah menguji kelayakan modul praktikum mikroprosesor Z80 dengan alat bantu Z80 Simulator sebagai media pendukung alternatif pada Mata Kuliah Praktik Sistem Mikroprosesor, khususnya tentang mikroprosesor Z80 [1]. Penelitian lain rancangan sistem transduser suhu mengunaka mikroprosesor Z80 [2] . Perbedaan Artikel yang dibuat dengan penelitian sebelumnya adalah pemberian catu daya tambahan sebagai backup catu daya pada trainer Z80.

\section{Metode Penelitian}

Pada penelitian ini, dilakukan pembuatan perancangan sistem yang dapat mengontrol dan memberikan catu daya cadangan untuk memori SRAM pada Z80 Trainer dengan menggunakan baterai. Adapun metode yang dilakukan adalah eksperimen [3] dan perancangan sistem [4], [5] yang mencakup tahapan penelitian, blok diagram dan flowchart rangkaian.

\section{A. Tahapan Penelitian}

Tahapan penelitian digambarkan dan diuraikan pada gambar 1 .

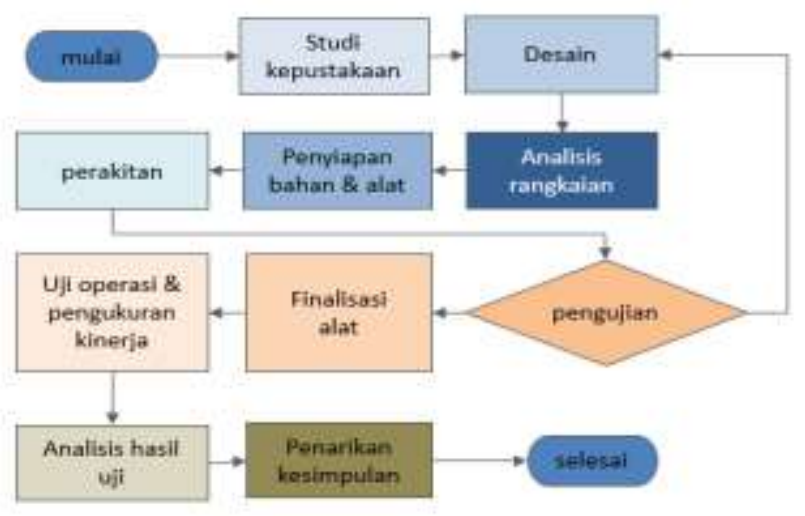

Gambar 1. Tahapan penelitian

\section{B. Blok Diagram}

Blok diagram rangkaian alat dapat dilihat pada gambar 2.

Catu Daya Cadangan

Catu Daya Utama

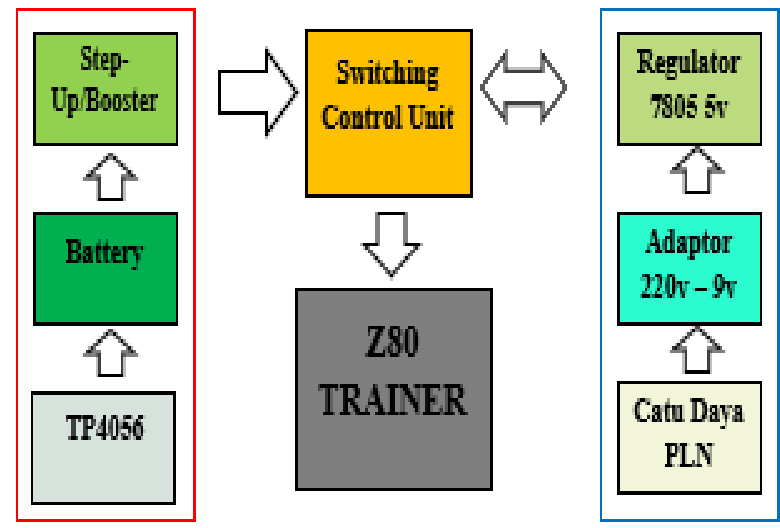

Gambar 2. Blok diagram rangkaian alat

Pada gambar 2, menjelaskan suatu rangkaian yang saling berhubungan antara satu dan lainnya dan Switching Control Unit sabagai pengendali catu daya Z80 Trainer atau pengendali catu daya cadangan SRAM. Catu daya utama $(P L N)$ dapat memasok daya listrik melalui adaptor konverter $220 \mathrm{v}$ to $9 \mathrm{v}$ yang melalui regulator untuk menurunkan tegangan dari $9 \mathrm{v}$ to $5 \mathrm{v}$ yang memasok rangkaian Switching Control Unit. Z80 Trainer akan mendapatkan suplai daya listrik jika catu daya PLN ada yang masuk dirangkaian Switching Control Unit dan dibandingkan dengan catu daya baterai $4,6 v$ yang melalui step-up/booster untuk dinaikkan dari 3,7v ke $5 v d c$, otomatis akan memasok rangkaian Switching Control Unit jika catu daya utama $(P L N)$ tiba-tiba terputus. Catu daya baterai hanya akan menggantikan atau menjaga daya listrik di $S R A M$, dan jika ingin menggunakan catu daya baterai untuk menghidupkan Z80 Trainer, terdapat saklar single on-off untuk dapat diaktifkan secara manual, akan tetapi penggunaan arus baterai sangat besar sehingga mengakibatkan atau berkurangnya durasi baterai dalam menjaga memori.

\section{Flowchart Rangkaian}

Flowchart rangkaian digambarkan pada gambar 3.

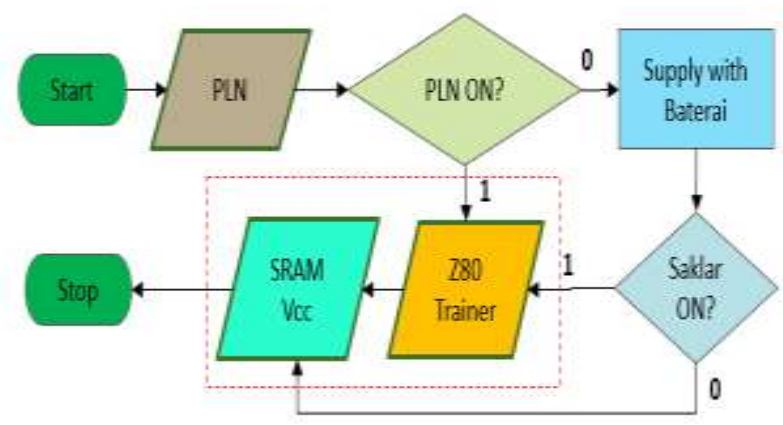

Gambar 3. Flowchart rangkaian

Pada gambar 3 merupakan flowchart diagram alur kerja rangkaian, diantaranya : Pada saat catu daya tegangan utama ada $\left(V_{\text {in }}\right)$ kondisi akan menanyakan apakah $V_{\text {in }}$ bernilai 1 , 
jika YA Z80 Trainer akan hidup $(O N)$, maka catu daya baterai $\left(V_{\text {backup }}\right)$ tidak akan memasok SRAM; Selanjutnya apabila daya listrik utama $V_{\text {in }}$ tidak ada (bernilai 0 ) maka catu daya baterai $\left(V_{\text {backup }}\right)$ yang akan mengambil alih sumber tegangan; Pada saat catu daya baterai $V_{\text {backup }}$ mengambil alih sumber listrik, kondisi menanyakan apakah saklar (S) bernilai 0 atau 1; Jika saklar bernilai 1 maka Z80 Trainer akan langsung hidup (ON), dan Apabila bernilai 0 maka catu daya baterai $V_{\text {backup }}$ akan memasok dan menjaga daya listrik di SRAM saja agar tetap konstan sehingga data terjaga.

\section{HASil dan Pembahasan}

Hasil yang diperoleh pada penelitian ini mencakup bagaimana unjuk kerja alat dapat mengontrol catu daya berasal dari baterai melalui rangkaian catu daya cadangan dan switching control unit serta pengujian alat keseluruhan Z80 Trainer. Pada perancangan catu daya cadangan baterai ini, terdiri dari beberapa bagian modul yang digabungkan menjadi suatu skema rangkaian, sehingga membentuk satu rangkaian alat utuh dan berfungsi sebagai pemasok daya listrik cadangan untuk SRAM. Adapun skema rangkaian yang dimaksud dapat dilihat pada gambar 4 .

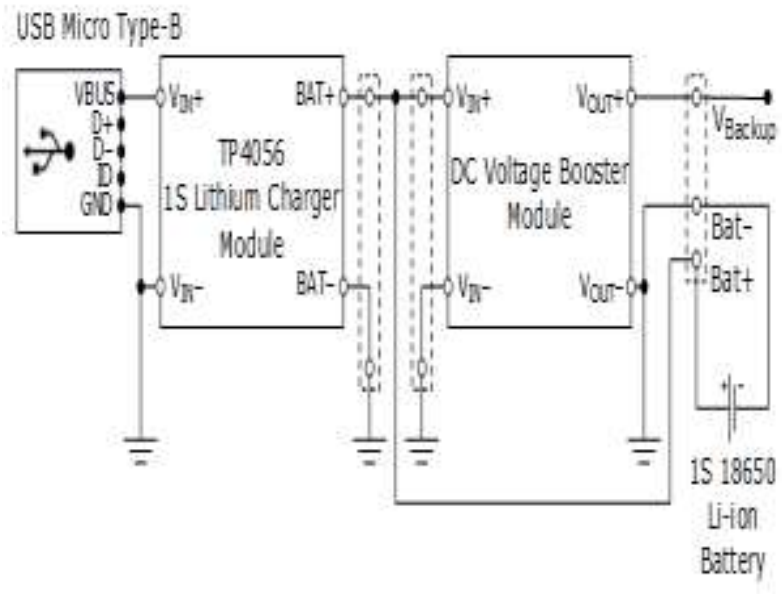

Gambar 4. Skema catu daya cadangan baterai

\section{A. Switching Control Unit}

Rancangan switching control unit ini juga, terdiri dari beberapa modul dan komponen-komponen kecil seperti resistor, transistor, kapasitor dan dioda serta komponen lainnya, yang digabungkan menjadi suatu skema rangkaian sehingga membentuk satu rangkaian alat dan berfungsi sebagai saklar atau penggantian catu daya cadangan jika pemasok catu daya PLN tiba-tiba padam. Adapun skema rangkaian yang dimaksud dapat dilihat pada gambar 5 .

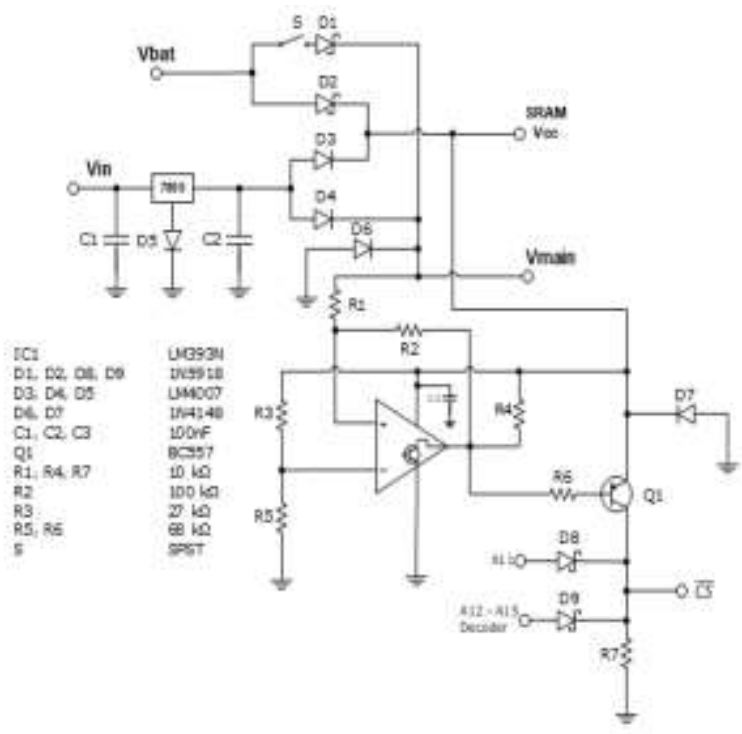

Gambar 5. Skema switching control unit

\section{B. Pengujian Alat Keseluruhan}

Pengujian dilakukan dengan menguji satu persatu blok rangkaian penyusun alat, dimulai dari pengujian catu daya cadangan baterai dan pengujian rangkaian kontrol pensaklaran (switching control unit). Setelah semua blok rangkaian diuji, selanjutnya dilakukan pengujian alat secara keseluruhan dengan menghubungkan semua blok dimaksud menjadi satu kesatuan utuh. Adapun skema alat keseluruhan dan bentuk fisik alat dapat dilihat pada gambar 6 dan gambar 7.

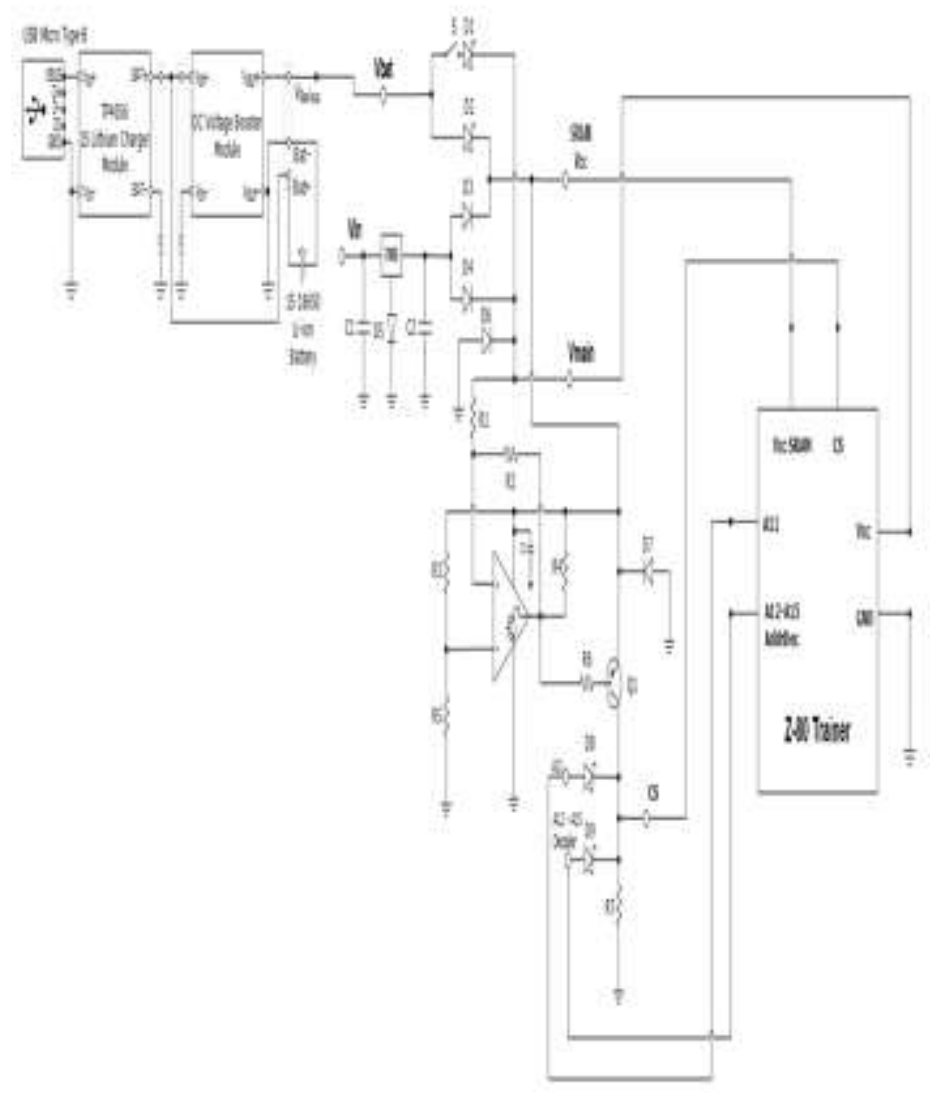

Gambar 6. Skema alat keseluruhan 


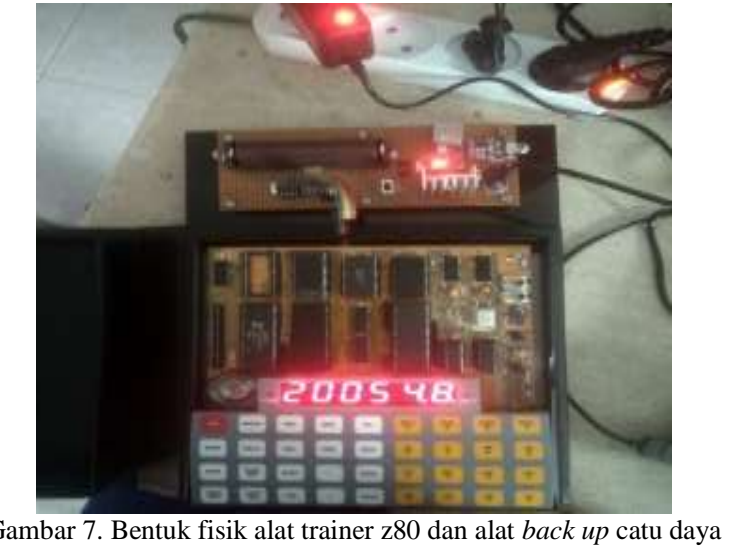

\section{Analisis Daya}

Pengujian catu daya dan battery backup ini bertujuan untuk mengetahui kehandalan catu daya terhadap memori SRAM [6]. Kapasitas baterai yang digunakan pada penelitian untuk pemasok catu daya cadangan $3000 \mathrm{mAh}$ dan pemakaian arus pada $S R A M$ sendiri sebesar $100 \mathrm{~mA}$.

Berdasarkan pemakaian daya yang berasal dari baterai maka analisis pengujian dan penggunaan daya baterai merupakan perhitungan berapa lama kapasitas baterai untuk memasok daya listrik pada SRAM. Rata-rata pemakaian arus pada 5 Volt adalah $100 \mathrm{mV}$ jadi total daya adalah $500 \mathrm{~mW}$, yakni bisa dituliskan $100 \mathrm{~mA} \times 5 \mathrm{~V}=500 \mathrm{~mW}$.

Pada bagian DC to DC memiliki efisiensi $\pm 90 \%$ dan untuk $500 \mathrm{~mW}$ akan menarik daya sebesar $\frac{500 \mathrm{~mW}}{90 \%}=555,5 \mathrm{~mW}$.

Bila sumber menggunakan baterai lithium dengan kapasitas muatannya $3000 \mathrm{mAh}$ dan tegangan rata-ratanya sebesar 3,7 volt maka baterai ini memiliki kapasitas daya sebesar :

$3,7 \mathrm{~V} \times 3000 \mathrm{mAh}=11100 \mathrm{mWh}$

Jadi lama waktu pemakaian lebih kurang adalah:

$$
\frac{11100 \mathrm{mWh}}{555,5 \mathrm{~mW}}=19,98 \mathrm{~h} \text { atau } 20 \mathrm{~h}
$$

Pemakaian arus untuk menjaga muatan SRAM kurang lebih 3,2 mA (sudah termasuk lampu indikator LED pada DC to DC pada modul).

Pemakaian daya menjadi $3,2 \mathrm{~mA} \times 5 \mathrm{~V}=16 \mathrm{~mW}$

Bila efisiensi modul adalah $90 \%$ atau 0,9 maka daya sebenarnya menjadi;

$$
\frac{16 \mathrm{~mW}}{0,9}=17,7 \mathrm{~mW}
$$

Jadi kapasitas baterai adalah $11100 \mathrm{mWh}$, maka akan habis dalam waktu:

$$
\frac{11100 \mathrm{WH}}{17,7 \mathrm{~mW}}=627,11 \mathrm{~h} \text { atau } \frac{627,11 \mathrm{H}}{24}=26 \text { hari }
$$

Pada prinsipnya perancangan alat catu daya cadangan untuk SRAM yang digunakan dalam praktikum dapat berfungsi dengan baik dengan analisis penggunaan baterainya.

\section{KESIMPULAN}

Penelitian ini telah menghasilkan sebuah alat yang dapat mengontrol catu daya cadangan berasal dari baterai melalui rangkaian switching control unit untuk SRAM di Z8O Trainer, dan selanjutnya mampu mendeteksi terputusnya suplai daya dari tegangan listrik PLN untuk memastikan bahwa data dan program yang telah ditulis dan tersimpan di memori tidak terhapus.

Hasil pengujian unjuk kerja alat didapatkan bahwa alat yang telah dibuat dapat mengontrol atau mengatur catu daya di SRAM jika tiba-tiba catu daya utama PLN terputus, sehingga data atau program yang ditulis akan terjaga dan tersimpan dengan aman di memori selama kurang lebih 26 hari, dengan memakai baterai Li-Ion tipe 18650 yang berkapasitas sebesar $3000 \mathrm{mAh}$ dan waktu penggunaan atau pengoperasian alat pada kondisi normal dengan menggunakan catu daya cadangan adalah $\pm 20 \mathrm{jam}$.

\section{Saran}

Pada penelitian yang telah dilakukan masih terdapat banyak kekurangan, sehingga pengembangan lebih lanjut dapat diupayakan untuk mengkoneksikan Z80 Trainer ini ke system PC (Personal Komputer) ataupun Laptop, sehingga proses penulisan program dapat berlangsung dengan lebih mudah dan lebih cepat serta menyenangkan.

\section{REFFERENSI}

[1] J. T. Elektro, F. Teknik, and U. N. Semarang, "Z80 SIMULATOR SEBAGAI ALAT BANTU PEMBELAJARAN SISTEM MIKROPROSESOR Z80," 2016.

[2] D. Isi, "Rancangan sistem tranduser suhu berbasis mikroprosesor z80," pp. 21-22, 2006.

[3] S. Abdussamad, "Rancang Bangun Inverter Mini 1.5 Vdc to 220 Vac Untuk Lampu Darurat," J. Tek., vol. 18, no. 1, pp. 7-16, Jun. 2020.

[4] M. R. Wirajaya, S. Abdussamad, and I. Z. Nasibu, "Rancang Bangun Mesin Penetas Telur Otomatis Menggunakan Mikrokontroler Arduino Uno," Jambura J. Electr. Electron. Eng., vol. 2, no. 1, pp. 24-29, Feb. 2020.

[5] A. W. A. Antu, S. Abdussamad, and I. Z. Nasibu, "Rancang Bangun Running Text pada Dot Matrix 16X160 Berbasis Arduino Uno Dengan Update Data System Menggunakan Perangkat Android Via Bluetooth," Jambura J. Electr. Electron. Eng., vol. 2, no. 1, pp. 8-13, Jan. 2020.

[6] Y. H. Kanoi, S. Abdussamad, and S. W. Dali, "Perancangan Jam Digital Waktu Sholat Menggunakan Arduino Uno," Jambura J. Electr. Electron. Eng., vol. 1, no. 2, pp. 32-39, Oct. 2019. 